\title{
Gross motor skills in children with Attention Deficit Hyperactivity Disorder
}

\author{
Gloria Rifilwe Pila-Nemutandani, BA, BA Hons, M Clinical Psychology (North-West University) \\ Lecturer/Clinical Psychologist. Department of Behavioural Medicine, School of Health Science, University of Kwa-Zulu Natal,
}

Basil Joseph Pillay, BA, BA Hons, LLM (Medical Law), DHSM, MA Clinical Psychology, PhD

Professor, Behavioural Medicine, Nelson R Mandela School of Medicine, School of Nursing and Public Health, University of KwaZulu Natal; Clinical Psychologist. Department of Behavioural Medicine, School of Health Science, University of Kwa-Zulu Natal

\section{Anneke Meyer, Higher Education Diploma, BSc Biological Sciences, MA Psychology, PhD}

Honorary Professor, University of KwaZulu Natal. Department of Behavioural Medicine, School of Health Science, University of Kwa-Zulu Natal

Introduction: The purpose of the study was to compare gross motor skills in children with and without Attention-Deficit/Hyperactivity Disorder (ADHD) symptoms. Children diagnosed with ADHD encounter difficulties in many areas of daily living activities that require motor coordination skills and often perform poorly on motor skills tests.

Method: A hundred and sixty primary school children ( 80 with ADHD and 80 controls) between 7-13 years, both females and males, participated in the study. Simple gross motor skills tasks such as walking, standing, catching, dribbling and kicking tasks were employed. The results were compared for gender and age.

Results: The children with ADHD showed poorer performance on all tasks. The gender of the participants influenced performance on kicking and dribbling tasks.

Conclusion: An association between the symptoms of ADHD and gross motor control was demonstrated, implying the need to include gross motor tasks or tests in assessments and interventions of children with ADHD.

Key words: ADHD, Gross motor skills, simple gross motor tasks, gender differences

\section{INTRODUCTION}

Attention Deficit Hyperactivity Disorder (ADHD) is considered a neurodevelopmental disorder with inattention, impulsiveness and hyperactivity as the core symptoms' ${ }^{\prime}$ with an estimated prevalence of $5 \%$ among children and adolescents world-wide ${ }^{2}$ as well as in South Africa ${ }^{3}$. The level of attention of ADHD children is often considered inappropriate for their age and they have trouble concentrating, appear not to listen and are easily distracted. The impulsiveness domain is often seen as difficulty in self-restraint while the hyperactivity domain is associated with symptoms like fidgetiness and difficulty sitting in one place for any extended period. These symptoms are considered to be impaired in social, academic and occupational settings ${ }^{2}$. Studies indicate that the disorder is more prone in males than in females ${ }^{3}$, therefore gender together with age, intelligence and comorbid disorders may further complicate the clinical manifestation and possibly the motor aspect of the disorder. The current study attempts to highlight gross motor characteristics or deficiencies encountered by children with ADHD.

\section{LITERATURE REVIEW}

Children with ADHD often experience difficulties performing tasks that require motor control. Studies suggest a greater role of motor factors in ADHD than was considered before ${ }^{4}$. Adi-Japha and Fox ${ }^{5}$ cited Mostofsky, et $\mathrm{al}^{6}$ in reporting deficits in performance speed on simple movement sequences in individuals with ADHD. The authors further indicated that deficits were restricted to accuracy of performance in children with $\mathrm{ADHD}^{7}$. Children with $\mathrm{ADHD}$ are said to be impaired or have immature inhibition of unintentional movements in the performance of repetitive motor tasks ${ }^{6}$. Scharoun et $\mathrm{a}^{8}$ found significant differences in foot tapping between children with $A D H D$ and a normal developing control group while other findings ${ }^{9}$ support the notion that children with ADHD show deficits in lower limb motor control. However, balance does not seem to be affected ${ }^{10}$.

Deficits in Attention, Motor Control and Perception (DAMP) is often used in Scandinavian countries to highlight the concept of motor deficits within the ADHD spectrum. DAMP is a key concept that involves a combination of motor control and perceptual problems co-occurring with attentional problems observed in children who do not show mental retardation or cerebral palsy ${ }^{11,12}$. Fine motor skills in children with ADHD are well-documented ${ }^{13-16}$, but there is less information on gross motor control. Piek \& Pitcher ${ }^{17}$ demonstrated significantly poorer movement ability in children with ADHD consistent with Developmental Coordination Disorder (DCD). The overlap between problems with motor coordination or clumsiness with inattention, hyperactivity and impulsiveness further highlights the complexities between ADHD and DCD ${ }^{4,14}$.

Piek \& Pitcher ${ }^{17}$ found that children with ADHD-Predominantly Inattentive subtype (ADHD-PI) had more problems with fine motor control, while children with ADHD-Combined (ADHD-C) subtype were found to experience significantly greater difficulty with gross motor skills. A subsequent study by the same authors ${ }^{18}$ established that a high percentage of children with ADHD displayed movement difficulties consistent with $D C D$, although less severe for the ADHD-Hyperactive/Impulsive (ADHD-HI) group than for the ADHD-PI and ADHD-C groups. Tseng et al ${ }^{19}$ found significant differences in children with and without ADHD in both fine and gross motor skills. A stepwise regression of their data showed that 
attention, impulse control and activity level were the three best predictors of problems with gross motor skills, while only attention and impulse control predicted deficiencies in fine motor control. The fact that activity level was a predictor for gross motor control but not for proficiency in fine motor tasks may suggest that different processes may be involved in the neurobiological pathways of the disorder.

A study by Fliers and Rommelse ${ }^{4}$ reported that about one third of children with ADHD had problems with motor coordination. The authors found that problems of motor control were related to inattentive rather than hyperactive/impulsive symptoms in both boys and girls. Comparing two groups of children with ADHD (those on medication and those not on medication) with a control group without ADHD, Verret, Gardiner and Beliveau ${ }^{20}$ found significant deficiencies in gross motor functions (locomotion) in both ADHD groups and that stimulant medication did not make a significant difference between the two groups. However, in a similar study, Bart, Podoly and Bar-Harm ${ }^{21}$ found that participants medicated with methylphenidate performed significantly superior on gross motor skills. The findings suggest that methylphenidate improves motor coordination in children with comorbid ADHD and DCD.

The dopaminergic fronto-striatal network has been implicated in the pathophysiology of ADHD (lateral prefrontal cortex, dorsal anterior cingulate cortex, the caudate nucleus and putamen) ${ }^{22}$. Other cortical regions such as the cerebellum, temporo-parietal lobes and the corpus callosum have also been implicated ${ }^{23-25}$. The cerebellum has been found to be responsible for motor control but it has also been implicated in cognitive and affective functions and cerebellar-cortical connections with regions involved in higherorder functions such as the prefrontal cortex ${ }^{26}$. Wyciszkiewicz, Pawlak and $\mathrm{Krawiec}^{27}$ found that individuals with ADHD had significantly smaller total cerebellar volumes which could be due to delayed or disrupted cerebellar development and contributory to ADHD pathophysiology. The involvement of the dopamine system in the aetiology of ADHD, is generally accepted ${ }^{28}$. Tripp and Wickens ${ }^{29}$, reported that it is the substantia nigra dopamine neurons projecting to the dorsolateral striatum that are involved in motor control, while the ventral tegmental area neurons project more ventro-medially and are involved in cognitive or affective functions. Sagvolden et $\mathrm{a}^{28}$ hypothesised that the neurobiological basis of deficient motor skills is predicted to be a hypo-functioning nigro-striatal dopaminergic system.

\section{METHOD}

\section{Study method}

This paper forms part of a larger study that included investigation into the lateralisation and motor functioning in children with ADHD. A case control study with children with ADHD symptoms and control group were compared and matched for age and gender.

\section{Ethical considerations}

The Humanities and Social Sciences Research Ethics Committee of the University of Kwa Zulu-Natal, approved the study (HSSOI73/0 I5D). The Department of Education in the Limpopo and North-West Provinces also approved the study. Consent was sought from the parents or caretakers and assent was obtained from the learners.

\section{Population and sampling procedure}

The participants were primary school children between 7 - 13 years who were screened for ADHD symptoms. The participants were from five schools in the Limpopo Province and five schools in the North-West Province, South Africa. Stratified random sampling was used to ensure representation of language groups namely Tswana, Sepedi, English and Tsonga. One hundred and sixty children were classified into two groups: the control group, without ADHD symptoms $(n=80)$ and those with ADHD $(n=80)$. The control and ADHD groups were matched for age and gender. Participants who had: IQ scores below average, a history of epilepsy, auditory and visual impairments and a physical disability as reported by their parents were excluded from the study.

\section{Measures}

The Disruptive Behaviour Disorders Rating Scale (DBD) consisting of 42 items was used ${ }^{30-32}$. The Scale has four sub-scales: inattention ( 9 items), hyperactivity/impulsiveness ( 9 items), Oppositional Defiance Disorder (8 items), and Conduct Disorder (16 items). The DBD was translated into Tswana, Sepedi and Tsonga and standardised for all population groups in the Limpopo Province ${ }^{3}$. The participants' teachers and parents rated their behaviour on each item of the DBD using a 4-point Likert scale, ranging from 0 (not at all) to 3 (very much). Participants with $\geq 93$ percentile scores were assigned to the ADHD group ${ }^{33}$ and those who scored $\leq 75$ th percentile constituted the control group.

A demographic questionnaire devised by the researchers as well as Home Situation Questionnaires (HSQ) were also completed by the parents of children in both groups ${ }^{34}$. The demographic questionnaire included developmental and medical history. The HSQ was used to assess specific situations in which problem behaviours occur and obtain an impairment index to confirm symptoms of ADHD.

The catching task involved the instructor and participants standing at 5-metres apart from each other. The ball was thrown by the instructor for the child to catch. Each time the ball was caught a score of one was allocated with a maximum score of three for the three trials. Participants had three trials for each hand which was scored from 0-3 for catching. The walking task required participants to walk along a straight five-metre line with both feet touching the line. Online and offline touches or steps scores were recorded. The walking task was not timed but the participants were instructed to do the task as fast as possible. The standing task involved the participants standing on one foot for as long as possible and the total time in seconds for each foot was recorded. The timer was stopped once the participant hopped or the opposite foot touched the floor. On the dribbling task, participants manoeuvred a ball around three obstacles (9" bright orange agility cones). About three agility cones were set in a straight line at a metre apart and a tennis ball placed at a metre before the first cone serving as a starting line. The participant was instructed to dribble the ball around each cone as fast as possible using only one foot. The correct (without the cone falling or losing the ball) manoeuvre around each cone scored one and a total of three scored was the maximum score. The kicking task required the participant to kick a ball using one leg. The participants were instructed to kick the ball into a $40 \mathrm{~cm}$ box target placed at about a 5 metre distance. Three trials with each foot was done, each with a score of one.

\section{Procedure}

The researcher explained to the school principals, teachers and parents of participating schools how to complete the questionnaires. Teachers completed the DBD questionnaires. After screening, the parents completed the biographical questionnaires, HSQ and the $\mathrm{DBD}$, thereby confirming the symptoms reported by the teachers. Based on the scores on the DBD, children were assigned to the ADHD and control groups. The assessments were done during school hours at the respective schools. None of the participants were on psychostimulant medication at the time of testing. One session of 45 minutes was allocated and the tasks followed the same order. The assessments were conducted by one research assistant who had an Honours in Psychology and two Clinical Psychologists.

\section{Data analysis}

Statistica $10^{35}$ and Statistical Package for Social Science version $21^{36}$ were used to analyse the data. Descriptive statistics and multivariate analysis of variance (MANOVA) were done. MANOVA has been indicated to compare several dependent variables' means across two or more groups. The Wilks lambda test was used to test whether there were differences between the means of the ADHD and the Control group on all the gross motor tasks (catching, standing, 
Table I: Descriptive statistics, MANOVA (Wilks Lambda test) results for the gross motor (walking, standing, catching, dribbling, and kicking) tasks, post hoc and gender effects results of the ADHD and the Control groups

\begin{tabular}{|c|c|c|c|c|c|c|c|c|}
\hline \multirow[t]{3}{*}{ Task } & & \multicolumn{2}{|c|}{$\begin{array}{c}\text { Descriptive } \\
\text { (Mean } \pm \text { SD) }\end{array}$} & \multicolumn{3}{|c|}{ MANOVA } & \multirow[t]{2}{*}{ Post hoc } & \multirow[t]{2}{*}{ Gender effect } \\
\hline & & ADHD & Control & DF & $\mathbf{F}$ & $\mathbf{p}$ & & \\
\hline & & $n=80(50 \%)$ & $n=80(50 \%)$ & & & & & \\
\hline \multirow[t]{2}{*}{ Walking } & On & $11.89 \pm 3.26$ & $12.96 \pm 3.74$ & 2,16 & 3.06 & $0.05 *$ & $0.05 *$ & Nil \\
\hline & Off & $0.45 \pm 1.09$ & $0.19 \pm 0.97$ & & & & 0.11 & \\
\hline \multirow[t]{2}{*}{ Standing } & Right & $41.58 \pm 30.64$ & $68.50 \pm 72.97$ & 2,16 & 5.70 & $0.00 *$ & $<0.001^{* *}$ & Nil \\
\hline & Left & $45.20 \pm 38.35$ & $69.96 \pm 62.91$ & & & & $<0.001^{* * *}$ & \\
\hline \multirow[t]{2}{*}{ Catching } & Right & $1.91 \pm 1.01$ & $2.55 \pm 0.76$ & 2,16 & 14.67 & $0.00 * *$ & $<0.001^{* * *}$ & Nil \\
\hline & Left & $1.48 \pm 1.03$ & $2.09 \pm 0.94$ & & & & $<0.001^{* * *}$ & \\
\hline \multirow[t]{2}{*}{ Dribbling } & Right & $2.36 \pm 0.93$ & $2.56 \pm 0.69$ & 2,16 & 3.58 & $0.03 *$ & 0.12 & \\
\hline & Left & $1.91 \pm 1.17$ & $2.33 \pm 0.94$ & & & & $0.005 *$ & Female \\
\hline \multirow[t]{2}{*}{ Kicking } & Right & $0.81 \pm 0.93$ & $1.49 \pm 1.14$ & 2,16 & 10.02 & $0.00 * *$ & $0.04 *$ & Male \\
\hline & Left & $0.64 \pm 0.77$ & $1.21 \pm 1.12$ & & & & $0.02 *$ & Male \\
\hline \multicolumn{9}{|c|}{${ }^{*} \mathrm{p} \leq 0.05, * * \mathrm{p} \leq 0.001$} \\
\hline
\end{tabular}

kicking, walking, and dribbling). Then post-hoc analysis (Bonferroni correction) was used to determine within-group differences.

\section{RESULTS}

The age of the participants between the two groups did not differ significantly: ADHD: $M=1 \mathrm{I} .22 \pm 1.43$ and Control: $M=1 \mathrm{I} .00$ $\pm 1.65, \mathrm{~F}(\mathrm{I}, \mathrm{I}$ (58) $=0.760, \mathrm{p}=0.38$. The MANOVA results for all the tasks are presented in Table $I$ including post hoc test values and gender effect.

There was a statistically significant difference $(F(2.16)=3.06$; $p=0.05$ ) between the ADHD and control groups only in the performance on the walking task. On the standing task, there were significant differences between the ADHD and Control group with both feet (Left foot: $F(2.16)=5.70 ; p<0.00$ I, Right foot: $F$ $(2.16)=5.70 ; p<0.00 I)$. With regards to the catching task, the difference in performance was significant between the ADHD and Control group $(F(2.16)=14.67 ; p<0.001)$ for both the left and right hands. There was no gender effect for walking, standing, and catching tasks, except for dribbling (i.e. left foot for girls) and kicking task (i.e. both feet for boys). There was no significant difference in dribbling between the ADHD and Control group with the right foot but a significant difference in performance was indicated with the left foot $(F(2.16)=3.58 ; p=0.03)$ where girls with ADHD performed significantly worse $(p<0.00 I)$ with the left foot than their control group counterparts. Finally, there was a significant difference in performance between the ADHD and Control group $(F(2.16)=10.02 ; p<0.00 I)$ on the kicking task. Post hoc results indicated significant differences in boys' performance with both the right and left foot (Right foot: $p=0.04$; Left foot: $p=0.02$ ) when the ADHD group was compared with the controls. Boys with ADHD performed significantly poorer on this task than the boys in the control group.

\section{DISCUSSION AND IMPLICATIONS}

The purpose of the current study was to establish whether deficiencies in performances on gross motor skills in children with ADHD occurred. On the five motor tasks administered, children with ADHD showed balance and control deficits. The results support the main aim of the study that differences in gross motor abilities in children with ADHD symptoms exist. Goetz et al ${ }^{37}$ implicate dynamic balance deficits contributing to children with ADHD performing poorly on balancing tasks. The authors reported that children with ADHD had greater sway amplitudes associated with $A D H D$ resulting in poor balance control. Other findings suggest that the balance deficits may reflect cerebellar dysfunctions ${ }^{38,39}$ and brain abnormalities at higher levels of cognitive, motor, and vestibular integration ${ }^{40}$.

In our study, the significant difference between the ADHD and control groups for standing on each leg is supported by literature ${ }^{41-43}$. However, one study by Schlee et al ${ }^{10}$ found no difference in performance when balancing on one leg. Difficulty standing on one leg (poor balance) in ADHD is said to be related to cerebellar dysfunctions ${ }^{44}$ and may pose executive control difficulties found in children with $\mathrm{ADHD}^{45}$. Further, a one leg standing task is considered a movement-and-balance skill task aimed at activating muscles that control the foot. The quality of movement could be a predictor of $A D H D^{41}$. It is important to note that an individual's failure to maintain adequate balance often leads to unwanted injuries and falls and children with ADHD have a tendency to bump into things'. The lack of gender effect on the standing task may indicate that ADHD symptomatology may be related to a balance deficit in both genders thus highlighting the same pathway involvement in the symptoms.

On the catching task, the ADHD group showed significantly poorer performance with both hands than the control group. Generally, performance is more proficient with the preferred hand, however the difference between the two hands is said to be typically greater in right than left handers, considering that left handers generally display less functional asymmetry than right hand$\mathrm{ers}^{46}$. However Jäncke et $\mathrm{a}^{47}$ reported that right handers require an increase in effort to perform with the left hand. The authors found that right handedness displays greater activation in the right hemisphere when using the left hand than in the left hemisphere when using the right hand. These findings are in contrast with this study's results where no significant difference was found between left-handed and right-handed performance and showed that significantly more children in the ADHD group were mixed handed while more in the control group were right dominant.

The results of the dribbling task showed that the females in the ADHD group performed poorer with the left foot than the control group, whereas on the kicking task the ADHD male group performed worse with both their feet. The difference in dribbling among the gender groups may be attributed to practise effect (i.e. in games involving the use of the legs - soccer) since primarily boys are involved in such play. Hence it is expected that boys would perform better on dribbling tasks. Haaland and Hoff ${ }^{48}$ demonstrated that non-dominant leg training improves bilateral motor performance in soccer. In addition, practicing a complex skill such as dribbling has shown performance improvements in the opposite (contralateral) limb ${ }^{49}$. Teixeira, Silva and Carvalho ${ }^{49}$ reported that 
the movement components transfer in a different direction and at a different magnitude, and that contralateral transfer effects are highly tasks specific and mostly asymmetric ${ }^{49}$. The left hemisphere is said to be involved in temporal and sequential control of movements and regulation of dynamic aspect, while the spatial orientation and coordination of actions are processed in the right hemisphere ${ }^{50}$. Such differences in the direction of inter-manual transfer may have practical implications in children with ADHD.

The literature supports the view of deficits in gross motor functioning, movement and fitness in ADHD sufferers. Poorer movement ability has been found in a study by Pitcher, Piek and $\mathrm{Hay}^{18}$, and furthermore, Harvey and Reid ${ }^{51}$ reported that children with ADHD are below average in fundamental gross performance and fitness. Harvey and Reid ${ }^{52}$ found that children with ADHD may be at risk for developmental delays in movement skill performance.

\section{CONCLUSION}

The current findings support the view that ADHD is associated with gross motor skills deficits such as balance and poor simple tasks performance. These skills are often important especially in daily life activities such as riding a bicycle, feeding, dressing, swimming, ball skills and tool use. Children with motor problems are said to be at risk for learning problems, lifestyle skills, and poorer social interpersonal relationships ${ }^{33,53-55}$. Given our findings, children with ADHD would be at greater risk of poor cognitive and social development which will contribute to poor self-esteem and depression. Our study recommends that the evaluation of children with ADHD must include the assessment of gross motor performance and its role in development. Further, interventions with children suffering from ADHD should also focus on activities that enhance and improve gross motor functioning.

The results of the study clearly implicates that motor-skill remediation is essential for children with ADHD, therefore it is advised that children referred to occupational therapists should be screened for symptoms of ADHD. It is well-known that symptoms of ADHD are variable and may be absent in a one-to-one situation as in assessment for occupational therapy. Assessment in a clinical situation should determine whether the basis of a child's motor problems is due to underlying motor problems or to the core symptoms of ADHD: hyperactivity, impulsiveness and/or inattention. When a child with ADHD is referred to occupational therapy with problems of motor functioning, clinical observations and standardised assessment can determine whether or not the child has co-morbid disorders or that the core symptoms of ADHD are the basis of the perceived motor difficulties.

When it is clear that the motor difficulties are related to ADHD, an adapted therapy programme should be followed: In addition to the usual programme, the children can be assisted in strategies to control impulsive behaviour and improve attention to tasks. The child should not be given tasks that are too challenging for their attention span, as this will affect the outcome of the remediating programme negatively. The therapy should be carried out in an environment free from distractions.

The evident association between ADHD and motor deficits as found in this study suggests that occupational therapy may be useful, not only in improving motor skills, but also in addressing the problem behaviours that children with ADHD exhibit, namely, disorganisation, problems with sustained attention, impulsiveness and hyperactivity.

\section{REFERENCES}

I. American Psychiatric Association. Diagnostic Statistical Manual of Mental Disorders: 5. American Psychiatric Association. 2013.

2. Polanczyk G, de Lima MS, Horta BL, Biederman J, Rohde LA. The worldwide prevalence of ADHD: a systematic review and metaregression analysis. American journal of psychiatry. 2007; 164 (6): 942-948.

3. Meyer A, Eilertsen D-E, Sundet JM, Tshifularo J, Sagvolden T. Crosscultural similarities in ADHD-like behaviour amongst South African primary school children. South African Journal of Psychology. 2004; 34(I): 122-38.

4. Fliers E, Rommelse N, Vermeulen S, Altink M, Buschgens C, Faraone $S$, et al. Motor coordination problems in children and adolescents with ADHD rated by parents and teachers: effects of age and gender. Journal of Neural Transmission. 2008; I I5(2): 2 I I-20.

5. Adi-Japha E, Fox O, Karni A. Atypical acquisition and atypical expression of memory consolidation gains in a motor skill in young female adults with ADHD. Research in Developmental Disabilities. 201 I; 32(3): $1011-20$.

6. Mostofsky SH, Rimrodt SL, Schafer JG, Boyce A, Goldberg MC, Pekar JJ, et al. Atypical motor and sensory cortex activation in attention-deficit/hyperactivity disorder: a functional magnetic resonance imaging study of simple sequential finger tapping. Biological psychiatry. 2006; 59(I): 48-56.

7. Silk T, Vance A, Rinehart N, Egan G, O'boyle M, Bradshaw J, et al. Fronto-parietal activation in attention-deficit hyperactivity disorder, combined type: functional magnetic resonance imaging study. The British Journal of Psychiatry. 2005; 187(3): 282-3.

8. Scharoun S, Bryden P, Otipkova Z, Musalek M, Lejcarova A. Motor skills in Czech children with attention-deficit/hyperactivity disorder and their neurotypical counterparts. Research in developmental disabilities. 2013; 34(I I): 4I42-53.

9. Pedersen SJ, Heath M, Surburg PR. Lower extremity response time performance in boys with ADHD. Journal of attention disorders. 2007; I0(4): 343-9.

10. Schlee G, Neubert T, Worenz A, Milani TL. Children with ADHD show no deficits in plantar foot sensitivity and static balance compared to healthy controls. Research in developmental disabilities. 2012; 33(6): 1957-63.

II. Gillberg C, Cederlund M. Asperger syndrome: familial and pre-and perinatal factors. Journal of autism and developmental disorders. 2005; 35(2): 159-66.

12. Rasmussen P, Gillberg C. Natural outcome of ADHD with developmental coordination disorder at age 22 years: a controlled, longitudinal, community-based study. Journal of the American Academy of Child \& Adolescent Psychiatry. 2000; 39(I I): I424-3 I.

13. Meyer A, Sagvolden T. Fine motor skills in South African children with symptoms of ADHD: influence of subtype, gender, age, and hand dominance. Behavioral and Brain Functions. 2006; 2(I): I.

14. Kaiser M-L, Schoemaker M, Albaret J-M, Geuze R. What is the evidence of impaired motor skills and motor control among children with attention deficit hyperactivity disorder (ADHD)? Systematic review of the literature. Research in developmental disabilities. 20I5; 36: 338-57.

15. Lavasani NM, Stagnitti K. A study on fine motor skills of Iranian children with attention deficit/hyper activity disorder aged from 6 to I I years. Occupational therapy international. 20I I; I8(2): I06-I4

16. Flapper BC, Houwen S, Schoemaker MM. Fine motor skills and effects of methylphenidate in children with attention-deficit-hyperactivity disorder and developmental coordination disorder. Developmental Medicine \& Child Neurology. 2006; 48(03): I65-9.

I7. Piek JP, Pitcher TM, Hay DA. Motor coordination and kinaesthesis in boys with attention deficit-hyperactivity disorder. Developmental medicine \& child neurology. 1999; 4I(3): I59-65.

18. Pitcher TM, Piek JP, Hay DA. Fine and gross motor ability in males with ADHD. Developmental Medicine \& Child Neurology. 2003; 45(8): 525-35.

19. Tseng MH, Henderson A, Chow SM, Yao G. Relationship between motor proficiency, attention, impulse, and activity in children with ADHD. Developmental Medicine \& Child Neurology. 2004; 46(6): $381-8$.

20. Verret C, Gardiner P, Béliveau L. Fitness level and gross motor performance of children with attention-deficit hyperactivity disorder. Adapted Physical Activity Quarterly. 2010; 27(4): 337-5I.

21. Bart O, Podoly T, Bar-Haim Y. A preliminary study on the effect of methylphenidate on motor performance in children with comorbid DCD and ADHD. Research in developmental disabilities. 2010; 3।(6): I443-7.

22. Emond V, Joyal C, Poissant H. [Structural and functional neuroanatomy of attention-deficit hyperactivity disorder (ADHD)]. L'encéphale. 2009; 35(2): I07-I4.

23. Cherkasova MV, Hechtman L. Neuroimaging in attention-deficit 
hyperactivity disorder: beyond the frontostriatal circuitry. The Canadian Journal of Psychiatry. 2009; 54(I0): 65I-64.

24. Berquin P, Giedd J, Jacobsen L, Hamburger S, Krain A, Rapoport J, et al. Cerebellum in attention-deficit hyperactivity disorder A morphometric MRI study. Neurology. 1998; 50(4): 1087-93.

25. Sowell ER, Thompson PM, Welcome SE, Henkenius AL, Toga AW, Peterson BS. Cortical abnormalities in children and adolescents with attention-deficit hyperactivity disorder. The Lancet. 2003; 362(9397): 1699-707.

26. Middleton FA, Strick PL. Cerebellar projections to the prefrontal cortex of the primate. The Journal of Neuroscience. 200 I; 2 I (2): $700-12$.

27. Wyciszkiewicz A, Pawlak MA, Krawiec K. Cerebellar Volume in Children With Attention-Deficit Hyperactivity Disorder (ADHD): Replication Study. Journal of child neurology. 20 I6; 32(2): 2I5-22I.

28. Sagvolden T, Johansen EB, Aase H, Russell VA. A dynamic developmental theory of attention-deficit/hyperactivity disorder (ADHD) predominantly hyperactive/impulsive and combined subtypes. Behavioral and Brain Sciences. 2005; 28(3): 397-4I8.

29. Tripp G, Wickens JR. Neurobiology of ADHD. Neuropharmacology. 2009; 57(7): 579-89.

30. Molina BS, Pelham WE, Blumenthal J, Galiszewski E. Agreement among teachers' behavior ratings of adolescents with a childhood history of attention deficit hyperactivity disorder. Journal of Clinical Child Psychology. 1998; 27(3): 330-9.

3I. Pelham WE, Gnagy EM, Greenslade KE, Milich R. Teacher ratings of DSM-III-R symptoms for the disruptive behavior disorders. Journal of the American Academy of Child \& Adolescent Psychiatry. 1992; 3I(2): 2I0-8.

32. Pillow DR, Pelham Jr WE, Hoza B, Molina BS, Stultz CH. Confirmatory factor analyses examining attention deficit hyperactivity disorder symptoms and other childhood disruptive behaviors. Journal of abnormal child psychology. 1998; 26(4): 293-309.

33. Barkley R, Murphy K. Attention Deficit Hyperactivity Disorder: A Clinical Workbook, Guildford Press. New York. 2006.

34. Barkley RA, Edelbrock C. Assessing situational variation in children's behavior problems: The Home and School Situations Questionnaires. Advances in behavioral assessment of children and families. 1987; 3: 157-76.

35. StatSoft I. STATISTICA, ver. I0. Tulsa, OK. 201 I.

36. Spss I. IBM SPSS statistics version 2I. Boston, Mass: International Business Machines Corp. 2012.

37. Goetz M, Schwabova JP, Hlavka Z, Ptacek R, Surman CB. Dynamic balance in children with attention-deficit hyperactivity disorder and its relationship with cognitive functions and cerebellum. Neuropsychiatric disease and treatment. 2017; 13:873.

38. Shaw P, Weingart D, Bonner T, Watson B, Park M, Sharp W, et al. Defining the neuroanatomical basis of motor coordination in children and its relationship with symptoms of attention-deficit/hyperactivity disorder. Psychological medicine. 2016: I.

39. Castellanos FX, Giedd JN, Marsh WL, Hamburger SD, Vaituzis AC, Dickstein DP, et al. Quantitative brain magnetic resonance imaging in attention-deficit hyperactivity disorder. Archives of general psychiatry. 1996; 53(7): 607-16.

40. Konicarova J, Bob P, Raboch J. Balance deficits and ADHD symptoms in medication-naive school-aged boys. Neuropsychiatric disease and treatment. 2013; 10: 85-8.

4I. Kroes M, Kessels AG, Kalff AC, Feron FJ, Vissers YL, Jolles J, et al. Quality of movement as predictor of ADHD: results from a prospective population study in 5-and 6-year-old children. Developmental Medicine and Child Neurology. 2002; 44(I I): 753-60.

42. Cheng J, Wang Y. Comparison of postural control between normal and attention deficit hyperactivity disorder boys. Beijing da xue xue bao Yi xue ban= Journal of Peking University Health sciences. 2007; 39(5): $53 \mid-4$.

43. Jucaite A, Fernell E, Forssberg H, Hadders-Algra M. Deficient coordination of associated postural adjustments during a lifting task in children with neurodevelopmental disorders. Developmental Medicine and Child Neurology. 2003; 45(II): 73I-42.

44. Raberger T, Wimmer $\mathrm{H}$. On the automaticity/cerebellar deficit hypothesis of dyslexia: balancing and continuous rapid naming in dyslexic and ADHD children. Neuropsychologia. 2003 ;4I(I I): I493-7.
45. Pennington BF, Groisser D, Welsh MC. Contrasting cognitive deficits in attention deficit hyperactivity disorder versus reading disability. Developmental Psychology. 1993; 29(3): 5 II.

46. Musalek M, Scharoun SM, Bryden PJ. Using Bishop's Card Reaching Task to Assess Hand Preference in 8-to 10-Year-Old Czech Children. PloS one. 2016; II(II): e0166337.

47. Jäncke L, Peters M, Schlaug G, Posse S, Steinmetz H, Müller-Gärtner $\mathrm{H}-\mathrm{W}$. Differential magnetic resonance signal change in human sensorimotor cortex to finger movements of different rate of the dominant and subdominant hand. Cognitive Brain Research. 1998; 6(4): 279-84.

48. Haaland E, Hoff J. Non-dominant leg training improves the bilateral motor performance of soccer players. Scandinavian journal of medicine \& science in sports. 2003; I3(3): 179-84.

49. Teixeira LA, Silva MV, Carvalho M. Reduction of lateral asymmetries in dribbling: The role of bilateral practice. Laterality: Asymmetries of Body, Brain and Cognition. 2003; 8(I): 53-65.

50. Sainburg RL. Evidence for a dynamic-dominance hypothesis of handedness. Experimental brain research. 2002; I42(2): 24I-58.

5I. Harvey WJ, Reid G. Motor performance of children with attentiondeficit hyperactivity disorder: A preliminary investigation. Adapted physical activity quarterly. 1997; 14(3): 189-202.

52. Harvey WJ, Reid G, Grizenko N, Mbekou V, Ter-Stepanian M, Joober R. Fundamental movement skills and children with attention-deficit hyperactivity disorder: peer comparisons and stimulant effects. Journal of abnormal child psychology. 2007; 35(5): 87I-82.

53. Sjöwall D, Roth L, Lindqvist S, Thorell LB. Multiple deficits in ADHD: executive dysfunction, delay aversion, reaction time variability, and emotional deficits. Journal of Child Psychology and Psychiatry. 2013; 54(6): 619-27.

54. Pliszka SR. Patterns of psychiatric comorbidity with attention-deficit/ hyperactivity disorder. Child and adolescent psychiatric clinics of North America. 2000.

55. Mayes SD, Calhoun SL, Crowell EW. Learning disabilities and ADHD: Overlapping spectrum disorders. Journal of learning disabilities. 2000; 33(5): 417-24. 